\title{
In Vitro Sensitivity Testing in the Assessment of Anti-CLL Drug Candidates
}

\author{
Günter Krause, Mirjam Kuckertz, Susan Kerwien, \\ Michaela Patz and Michael Hallek \\ Department I of Internal Medicine, University of Cologne, \\ Center of Integrated Oncology Köln Bonn, \\ Germany
}

\section{Introduction}

Chronic lymphocytic leukemia (CLL) is characterized by the accumulation of morphologically mature, but immuno-incompetent B-lymphocytes in the bone marrow, peripheral blood, spleen and lymphoid organs. With an annual incidence of about 2-3/ 100000 in the general population (Hamblin, 2009), CLL represents a frequent leukemia type. Since CLL mostly affects persons of advanced age, the incidence among persons above 65 years reaches ten times this frequency (Eichhorst et al., 2009). Moreover CLL follows a remarkably heterogeneous course, emphasizing the need for personalized treatment approaches. Despite recent advances in CLL therapy, the disease still remains incurable and new treatment options need to be developed (Hallek et al., 2008). New insights into CLL biology have started to result in new targeted, sometimes patient group-specific treatment approaches (Pleyer et al., 2009; Zenz et al., 2010). Candidate substances for pre-clincial assays are mostly molecularly targeted drugs, i.e. either small molecules interfering with intracellular signaling (Wickremasinghe et al., 2011) or mononoclonal antibodies (Jaglowski et al., 2010). As examples we will discuss in this chapter the pre-clinical assessment of protein and lipid kinase inhibitors and of monoclonal antibodies.

Since candidate substances with a potential for treating CLL become available at an increasing pace, there is a growing need for comprehensive laboratory assessment of these substances. For this purpose the effects of these drug candidates on fresh CLL lymphocytes are compared by means of viability and cytotoxicity assays with the aim of selecting suitable candidates for further development. In addition viability and cytotoxicity assays on CLL cells serve to prepare candidate substances for clinical trials and to determine, which subgroups of patients respond best, in the sense of personalized medicine. This endeavor constitutes the small excerpt of the drug discovery process immediately preceding clinical trials (Collins \& Workman, 2006). Since it links laboratory investigation and clinical application it can be understood as translational research, which is further underscored by patient samples being subjected to cultivation and observation in the laboratory. 
B lymphocytes freshly isolated from peripheral blood of CLL patients constitute a readily available source for the pre-clinical in vitro assessment of drugs and combinations with therapeutic potential for treating CLL. Due to the epidemiological features of CLL as a frequent chronic leukemia, with many patients living with the disease for extended periods, a continuous supply of blood samples can be made available and used in a meaningful manner by performing pre-clinical assays, which, according to the concept of translational medicine, in turn could lead to improved therapies. Drug assessment on fresh CLL samples can be performed rapidly and relatively conveniently by comparing untreated and treated in vitro cultures.

On the other hand, primary cultures of B cells freshly isolated from the peripheral blood of CLL patients often may represent an insufficient model for predicting clinical drug efficacy, since they are known to behave differently from CLL lymphocytes in their in vivo environment. This is evident from the obviously contrasting behavior of CLL cells in vivo and during in vitro culture. Whereas accumulation of CLL cells in vivo is thought to occur due to resistance towards apoptosis and a certain degree of cell proliferation, in vitro cultures spontaneously undergo apoptosis and show low viability and almost completely absent proliferation. Because this contrasting behaviour of CLL cells in vitro and in vivo can be attributed to a lack of the appropriate micro-environment during laboratory culture, the value of drug assessment on CLL lymphocytes ex vivo can be greatly enhanced by mimicking certain micro-environmental stimuli.

Commonly used cytotoxicity and viability assays are compiled in this chapter and will be discussed in the context of the assessment of potential anti-CLL drugs. On the level of individual susceptibility it is well established for chemotherapeutic agents that sensitivity of tumor cells in vitro corresponds to the probability of clinical response (Bosanquet et al., 2009). Therefore one would expect also for targeted drugs that in vitro assays enable to some degree the comparison of the efficacies of different agents and the prediction of the response of molecularly defined subgroups of CLL patients. As examples for correlations of molecularly defined patient subgroups with treatment susceptibility in vitro we name here the clearly higher dasatinib sensitivity of CLL samples with unmutated IgHV genes as compared to mutated ones (Veldurthy et al., 2008) or the correlation of the B cell depletion induced by CD20 antibodies with antigen expression on the surface of CLL cells (Patz et al., 2011).

In this chapter we review the pros and cons of pre-clinical drug assessment in comparatively simple ex vivo assays. The predictability of treatment out-come from in vitro cultures of CLL lymphocytes must be considered, since there are known limitations of the assay system, which can, however, be overcome to a certain degree by linking the results to investigations of target and cell type specificity.

\section{Performing cytotoxicity assays on CLL samples}

In the course of the pre-clinical assessment of anti-CLL drug candidates, in vitro cultures of CLL lymphocytes are treated with test substances. Subsequently dose-dependent treatment effects on the viability of CLL cells are recorded by means of established proliferation and cytotoxicity assays. These assays yield a first measure of drug potency for CLL lymphocytes, but certainly need to be rigidly controlled and standardized. Moreover they should be 
accompanied by biochemical assays in order to assure cell type and target specificity. Such comprehensive approaches will allow the design of meaningful drug combinations, which then are to be subjected to another round of in vitro sensitivity assays.

Cytotoxicity assays play a pivotal role in pre-clinical drug testing (Kepp et al., 2011) and many of them are suitable for assessing treatment effects on fresh CLL cells (Table 1). Some of these assays are based on absolute cell counts or less laborious surrogate parameters determining total cellular activities e.g. in colorimetric or fluorimetric non-clonogenic microculture assays (Lindhagen et al., 2008). In contrast, flow cytometric assays usually yield percentages of cells with certain properties within the investigated cell population unless they are standardized for the examined volume, e.g. by absolute counting beads.

\begin{tabular}{|c|c|}
\hline \multirow{5}{*}{$\begin{array}{l}\qquad \text { Method } \\
\text { cell counting } \\
\text { metabolic activity } \\
\text { ATP consumption } \\
\text { intracellular esterase } \\
\text { activity }\end{array}$} & Technological platform \\
\hline & light microscope \\
\hline & absorbance reader \\
\hline & luminometer \\
\hline & fluorimeter \\
\hline DNA replication & $\begin{array}{l}\text { absorbance reader } \\
\text { flow cytometry }\end{array}$ \\
\hline $\begin{array}{l}\text { phosphatidylserine } \\
\text { exposure }\end{array}$ & flow cytometry \\
\hline membrane disintegration & flow cytometry \\
\hline $\begin{array}{l}\Delta \psi \mathrm{m} \text { dissipation } \\
\text { morphology }\end{array}$ & $\begin{array}{l}\text { flow cytometry } \\
\text { flow cytometry }\end{array}$ \\
\hline $\begin{array}{l}\text { production of reactive } \\
\text { oxygen species }\end{array}$ & flow cytometry \\
\hline caspase activation & $\begin{array}{l}\text { flow cytometry } \\
\text { immunoblotting }\end{array}$ \\
\hline
\end{tabular}

parameters

trypan blue exclusion

tetrazolium salt reduction

luciferase activity

conversion of non-fluorescent

fluorescein diacetate

bromo-deoxyuridine

incorporation

annexin V-binding

staining with DNA intercalating

dye

fluorescent dye, e.g. DiOC6

forward scatter / side scatter

fluorigenic substrate,

e.g. CM-H2-DCF-DA

fluorescent substrates

detection of cleaved fragments

Table 1. Selected cytotoxicity and viability assays commonly used with CLL samples.

\subsection{Flow cytometric cell death and viability assays}

Flow cytometric assessment of phosphatidylserine exposure and membrane disintegration is among the viability and cytotoxicity assays most frequently applied for monitoring drug effects on CLL cells. Percentages of cell populations undergoing cell death can be determined by monitoring the loss of membrane asymmetry in early phases of apoptosis and subsequent membrane disruption (Fig. 1). This can be achieved by staining cells, e.g. B lymphocytes, with fluorescently labeled annexin $\mathrm{V}$, which binds to phosphatidylserine with high affinity (Koopman et al., 1994). Phosphatidylserine exposure accompanies early phases of apoptosis, before membrane disintegration of the cytoplasma membrane allows access of DNA intercalating dies to the nucleus. Counter-staining with DNA intercalating dyes originally served the distinction of apoptotic from necrotic cells. Analysis of annexin V binding or DNA staining can be replaced for staining with dyes indicating mitochondrial membrane potential, e.g. 3,3'-dihexyloxacarbocyanine iodide (DiOC6) (Stanglmaier et al., 
2004; Veldurthy et al., 2008), or reactive oxygen species, e.g. the fluorogenic chloromethyl2,7-dichlorodihydrofluorescein-diacetate (CM-H - -DCF-DA) (Lilienthal et al., 2011). Usually populations of CLL cells with phosphatidylserine exposure coincide with those showing typical morphological signs of apoptosis, i.e. reduced size and increased granularity as indicated by forward-scatter (FSC) and side-scatter (SSC) in the flow cytometer. Concerns have been raised about a possible over-estimation of drug effects due to flow cytometry artefacts. For instance, the widely used determination of phosphatidylserine exposure was claimed to over-estimate apoptosis induction in the extraordinarily fragile CLL cells due to in vitro handling during sample preparation for flow cytometry (Groves et al., 2009). Similarly antibody effects on CLL samples determined by flow cytometry were suspected of being misinterpreted owing to cell aggregation (Golay et al., 2010). These concerns can be overcome by parallel biological effect monitoring in several different assay systems as controls.

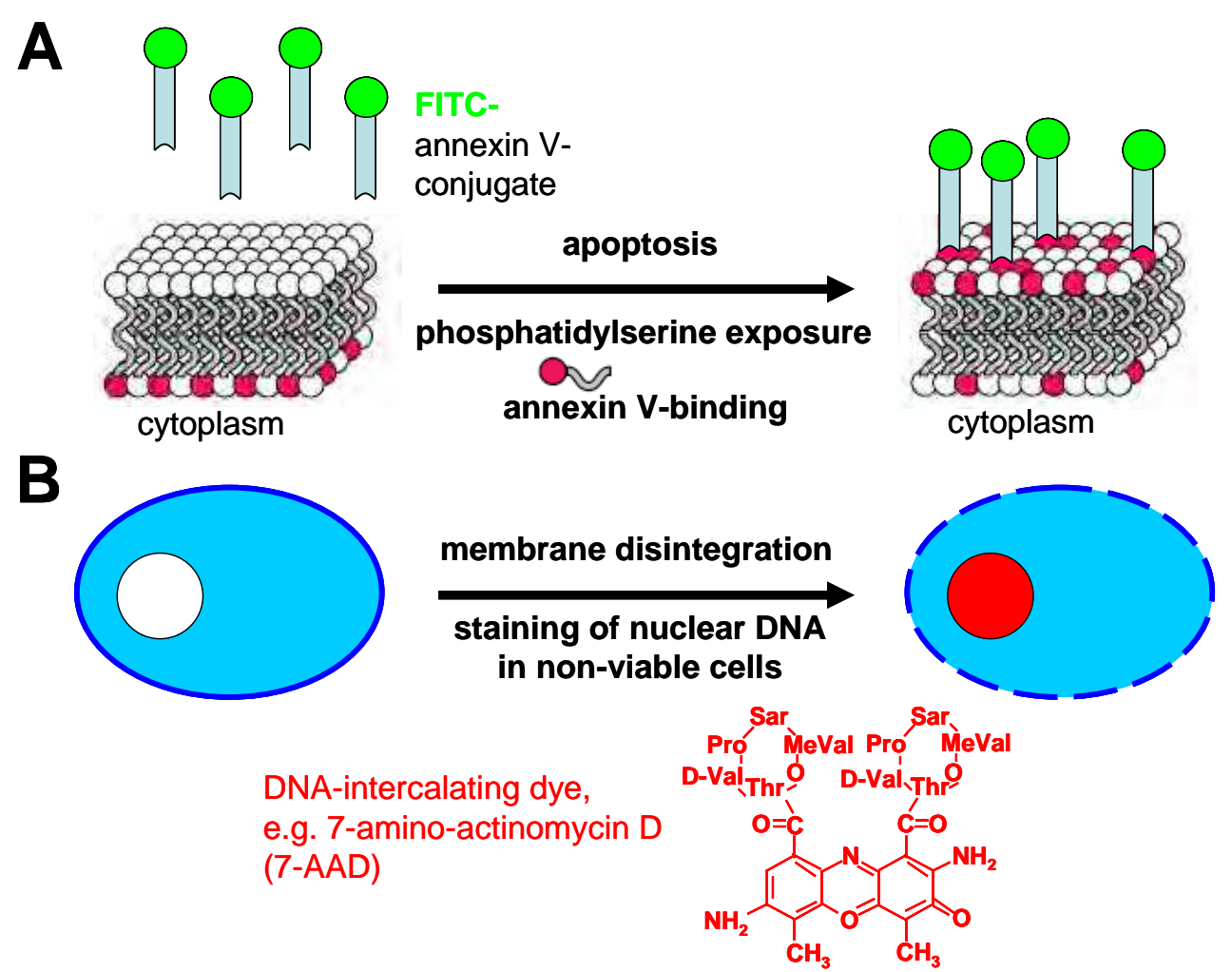

Fig. 1. Principle of a widely used assay for the determination of the percentages of apoptotic cells. The flow cytometric assessment of phosphatidylserine exposure (A) and membrane disintegration (B) can be performed simultaneously.

Part (A) adapted from Zhang et al., 1997 and Pharmingen, 1998. 


\subsection{Concentration dependence}

Investigation of the dose-dependency of drug effects is an important confirmation of any observations that by far surpasses the importance of repeated measurements. In addition, the shape of dose response curves sometimes can provide mechanistic clues, e.g. in the case of saturation effects. When drugs are investigated for CLL that previously have been preclinically developed or admitted for the treatment of other cancers, it is possible to consider achievable plasma concentrations for the in vitro assessment. Biological effect measurements obtained at multiple concentrations can be conveniently summarized by concentrations inhibiting $50 \%\left(\mathrm{IC}_{50}\right)$. These $\mathrm{IC}_{50}$ concentrations can be a useful manner of comparing the effects of different drugs or diverging sensitivities of different samples. In the case of saturation effects, as in the dose response of CLL lymphocytes to dasatinib (Veldurthy et al., 2008), it might be more appropriate to indicate the individual saturation levels of response rather than extrapolating $\mathrm{IC}_{50}$ concentrations. Moreover, investigators must not be misled by the convenience of such tabulated values to regard them as sample-specific constants and therefore to apply them to different assay types, since $\mathrm{IC}_{50}$ concentrations strictly depend on the type of assay performed (Krause \& Hallek, 2011).

\section{Mimicking micro-environmental interactions}

Considering the micro-environment of CLL cells may improve predictions of clinical drug efficacy from in vitro assays on fresh CLL samples. Regarding their resistance to apoptosis CLL cells in culture behave entirely differently from the situation in vivo, owing to dependence on their micro-environment. Therefore it is necessary to simulate certain microenvironmental stimuli for drug assessment in vitro, for instance following the approaches described in the following subchapters. A number of ligand/receptor pairs have been identified that activate CLL cells (Fig. 2) (Munk Pedersen \& Reed, 2004), among them the chemokine stroma-derived factor 1 , nowadays referred to as CXCL12 and its receptor CXCR4 on CLL cells, that belongs to the class of G-protein-coupled 7-transmembrane domain receptors (Burger \& Kipps, 2006) and VCAM-1 (CD106) expressed on the surface of stroma cells that interacts with the integrin VAL-4 (CD49a) on CLL cells (Burger et al., 2009). The strict dependence of CLL cells on the interactions with their environment is also apparent from the absence of good cell line models for CLL.

\subsection{B cell receptor stimulation}

Like for normal lymphocytes, also the fate of CLL cells is to a high degree determined by B cell receptor (BCR) stimulation (Stevenson \& Caligaris-Cappio, 2004). According to the degree of somatic hypermutation in rearranged antigen receptor genes, subgroups of CLL clones with immunoglobulin heavy chain variable region (IgHV) genes can be distinguished that reflect progressing B cell development stages corresponding to naïve or memory B cells. Usually the threshold separating these molecularly defined prognostic subgroups is set at 2 $\%$ sequence divergence of rearranged IgHV genes from the closest germline sequences. The CLL subgroups with unmutated or mutated IgHV genes have a widely different prognosis indicated by 24 versus 8 years median overall survival after diagnosis (Hamblin et al., 1999). High expression of zeta-assoziated protein 70 (ZAP-70) and of CD38 serve as surrogate markers of unmutated IgHV genes (Crespo et al., 2003; Hamblin et al., 2002). 
Antigen contact for CLL cells can be mimicked in vitro by crosslinking surface IgM by means of anti-IgM antibodies. Long lasting stimulation of the BCR leads to prolonged survival of CLL cells (Deglesne et al., 2006). This can be achieved by using soluble anti-IgM or anti-IgMcoated surfaces.

\subsection{CD40 stimulation}

The CD40 molecule expressed on the surface of CLL cells belongs to the tumor necrosis factor family and participates in antigen recognition as a co-receptor. Its cognate ligand, CD40 ligand (CD40L), also known as CD154, is expressed on the surface of activated T lymphocytes. Engagement of CD40 on CLL lymphocytes mimics the micro-environment inside lymph nodes and leads to protection against DNA damaging substances, e.g. chemotherapeutic agents. CD40L stimulation of CLL cells can be provided by co-culture with fibroblasts expressing recombinant CD154. For instance co-culture with CD40L expressing fibroblasts protects CLL cells from DNA damaging agents, but this effect can be partly reversed by the kinase inhibitor dasatinib (Hallaert et al., 2008). The sensitivity of CLL cells for the Bcl-2 antagonist ABT737 is decreased by a factor of 1000, if the CLL cells are cocultivated with fibroblasts expressing CD40L (Vogler et al., 2009).

\subsection{Stroma cell-derived soluble factors and cell surface interactions}

The soluble factors produced by bone marrow stromal cells include the chemokine CXCL12, which despite its original designation as stroma-cell derived factor is shown in Fig. 2 as a micro-environmental factor occurring in peripheral blood, owing to its alternate origin from nurse-like cells. Stimulation by purified recombinant CXCL12 induced the rafdependent mitogen activated protein (MAP) kinase cascades in CLL cells, which augmented their survival and was targeted by the raf inhibitor sorafenib (Messmer et al., 2011).

In vivo, inhibition of apoptosis may occur preferentially in pseudofollicles containing CLL and accessory cells, due to cell contact and mutual paracrine and autocrine stimulation. In vitro, co-culture with bone-marrow-derived stromal cells, e.g. the cell line HS-5, may provide stimuli for long-term survival of CLL cells. In co-cultures of primary CLL cells with HS-5 cells, various chemokines attracting T lymphocytes, most prominently CCL4 and CCL3, were detected, which are not produced by HS-5 control cultures (Seiffert et al., 2010). The proteins found in the supernatant of HS-5 co-cultures included factors, which are commonly secreted by monocytes, e.g. soluble CD14. Among the soluble factors provided to CLL cells by co-culture with the bone marrow stromal cell line HS5, vascular endothelial growth factor (VEGF) is partly responsible for the increase in viability of co-cultivated CLL cells (Gehrke et al., 2011).

\subsection{Oligonucleotides containing CpG dinucleotides}

Toll like receptor 9 (TLR9) has been identified as a part of the innate immune response recognizing unmethylated foreign DNA that can be mimicked by phosphothioate oligodeoxynucleotides containing CpG dinucleotides (CpG-ODN) (Krieg, 2006). Survival and proliferation of CLL cells can be considerably enhanced by class B CpG-ODN, e.g. DSPN-30 (Decker et al., 2000). Like CD40 ligation, activation of CLL cells through TLR9 
occupation by CPG-ODN was exploited as a mitogenic signal in order to obtain metaphase chromosomes for cytogenetic analysis by fluorescent in situ hybridization (Mayr et al., 2006). The importance of activated CLL cells in drug assessment is demonstrated by the example of mTOR inhibitors. In untreated CLL cells rapamycin showed an $\mathrm{IC}_{50}$ of $10 \mu \mathrm{M}$ for apoptosis induction (Aleskog et al., 2008). In contrast less than one thousandth of this concentration of RAD001 or $10 \mathrm{nM}$ rapamycin was sufficient for complete inhibition of the cell proliferation induced by CpG-ODN (Decker et al., 2003).

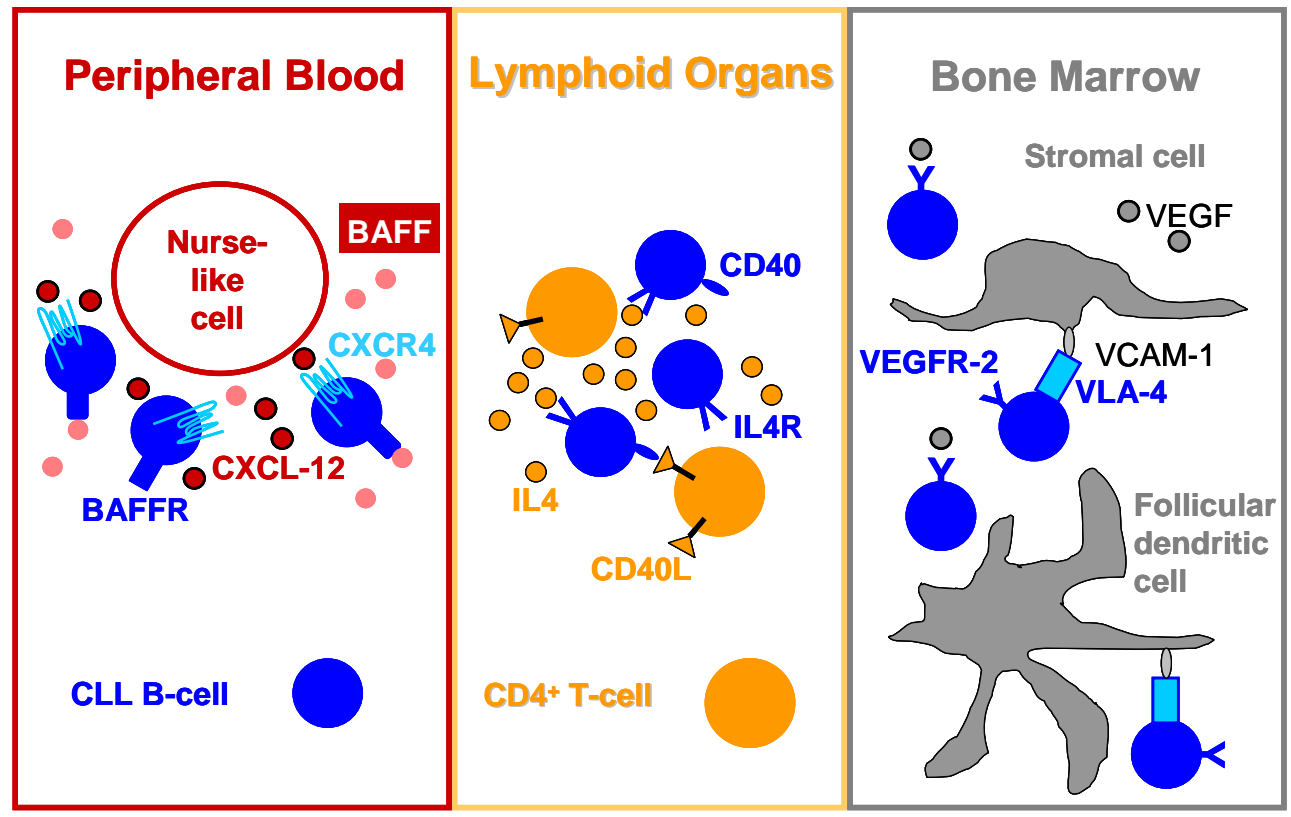

Fig. 2. Microenvironment interactions of CLL cells. The survival of CLL lymphocytes can be prolonged by contact with different accessory cells in the peripheral blood, lymphoid system and bone marrow. Some prominent interactions of CLL cells with soluble factors and cell surface molecules supplied by accessory cells are shown. On the surface of CLL cells receptors for various soluble factors are expressed, e.g. for the chemokine CXCL12, formerly designated as stroma-derived factor 1 (SDF-1), for the cytokine interleukin-4 (IL-4), and for vascular endothelial growth factor (VEGF). CD40 or the integrin VAL-4 on the surface of CLL cells interact with CD40 ligand (CD40L) on T cells or VCAM-1 on follicular dendritic cells and other stromal cells, respectively. Adapted from Munk Pedersen et al., 2004.

In addition to activating CLL cells CpG-ODN were found to increase surface expression levels of co-stimulatory molecules including CD20 (Jahrsdorfer et al., 2001). Consequently, the same CpG-ODN DSPN-30 that is commonly used for activating CLL cells, increased CD20 expression on freshly isolated CLL cells, which in turn led to higher B cell depletion by the type II CD20 antibody GA101 (Patz et al., 2011). 


\subsection{B cell depletion from whole blood samples}

Monoclonal antibodies (MABs) induce direct cell death (DCD) of tumor cells via signal transduction and additional Fc-mediated cytotoxic effects, namely antibody-dependent cell-mediated cytotoxicity (ADCC) and complement-dependent cytotoxicity (CDC) (Fig. $3)$. In order to include $A D C C$ and $C D C$ in measurements of overall MAB effects, the extent of tumor cell depletion by MABs from individual blood samples can be determined by multi-color flow cytometry comparing treated and untreated whole blood cultures.

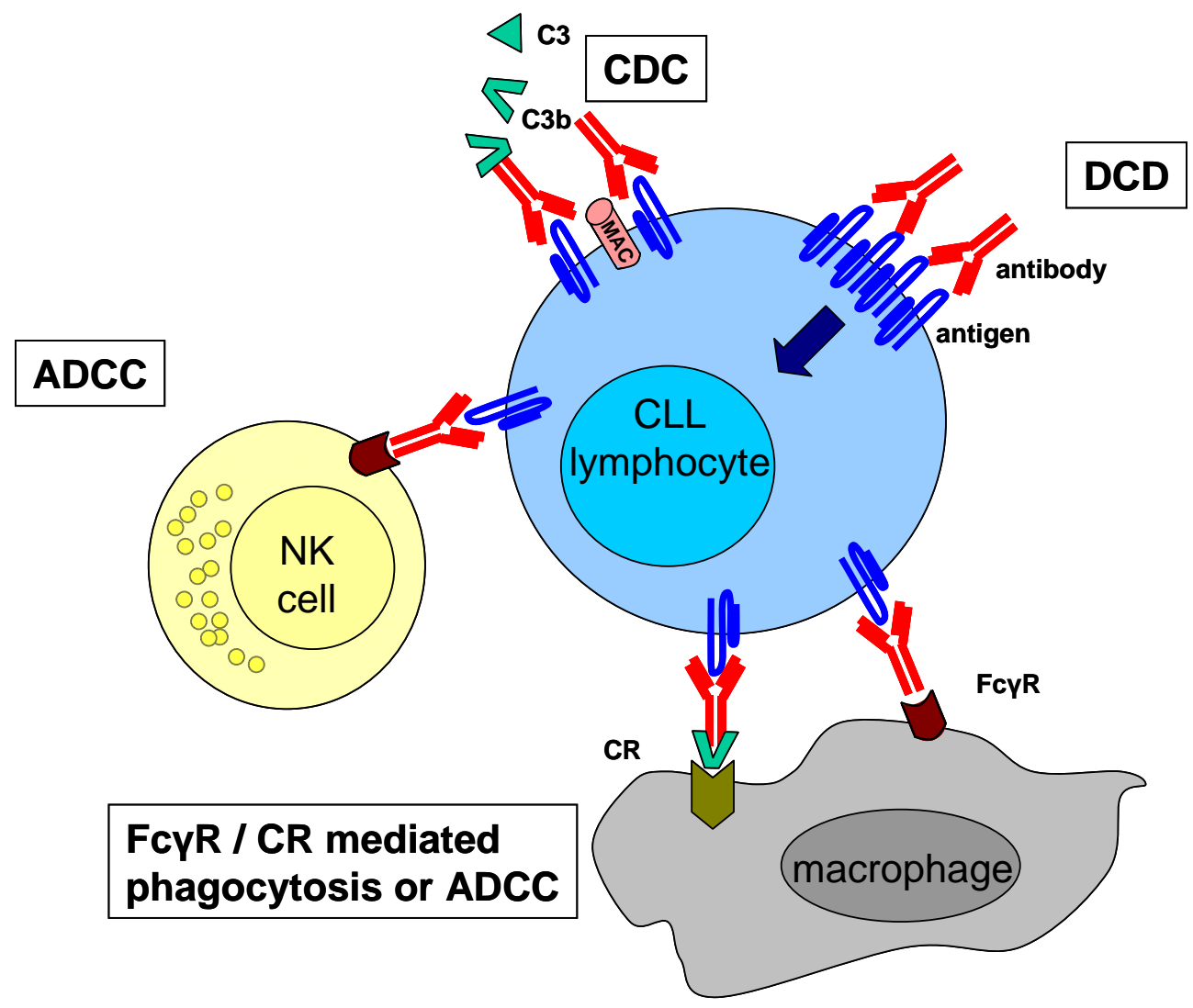

Fig. 3. Killing mechanisms of monoclonal antibodies and their assessment. Apart from direct cell death (DCD) induction in tumor cells, monoclonal antibodies exert their action via Fcmediated functions, namely complement-mediated cytotoxicity (CDC) and antibodydependent cell-mediated cytotoxicity (ADCC) and phagocytosis. Due to the importance of CD20 antibodies in CLL therapy, a structure crossing the cell membrane four times is shown as the surface antigen on CLL cells. This overall structural organization is shared by another emerging target for immunotherapy, the tetraspanin CD37. Ways to examine the above mechanisms on isolated CLL cells and whole blood samples are compiled in Table 2 and described in the text. Adapted from Olszewski \& Grossbard, 2004 and Jaglowski et al., 2010. 


\section{Pre-clinical assessment of kinase inhibitors}

Prototypic targeted therapy by the tyrosine kinase inhibitor imatinib was developed for Bcr$\mathrm{Abl}$ positive leukemias, in which deregulated $\mathrm{Abl}$ activity is a predominant driving force (Druker et al., 2001). In contrast, the pathogenesis of CLL appears to be multi-factorial. The second generation of $\mathrm{Abl}$ inhibitors for treatment of imatinib-resistant Bcr-Abl positive leukemias achieves greater efficacy against mutant forms of the Abl kinase (Weisberg et al., 2007). Some of these inhibitors, e.g. dasatinib (Shah et al., 2004) and bosutinib (Puttini et al., 2006) are dual-specific and target $\mathrm{Abl}$ and additionally Src kinases. Since members of the latter tyrosine kinase family, e.g. Lyn (Contri et al., 2005) and Lck (Majolini et al., 1999) have been suggested to be involved in CLL pathogenesis, we conducted an assessment of dasatinib on CLL cells (Veldurthy et al., 2008). This pre-clinical investigation indicated an influence of Src kinase inhibition on the cellular survival of CLL cells with preference for the subgroups with unmutated immunoglobulin heavy chain genes or with high ZAP70 expression and thus indicated patient groups that might profit most from Src kinase inhibition. Since the fate of CLL B lymphocytes critically depends on BCR signaling (Stevenson \& Caligaris-Cappio, 2004), inhibition by kinase inhibitors of survival pathways emanating from the BCR or from micro-environmental stimuli (Burger et al., 2009) represents a promising strategy for treating CLL (Gandhi, 2010).

Drug assessment on primary CLL cells serves as preparation for clinical trials and to some degree enables comparison of the efficacies of different agents and the prediction of the response of molecularly defined subgroups of CLL patients. The clearly higher dasatinib sensitivity of CLL samples with unmutated $\mathrm{IgV}_{\mathrm{H}}$ genes as compared to mutated ones is an example for this type of correlation (Veldurthy et al., 2008). Signaling analysis revealed that treatment of primary CLL cells with dasatinib drastically reduces the level of activated SFK in CLL cells, but inhibits downstream BCR signaling pathways and induces apoptosis more strongly in the patient subgroup with aggressive disease. The extent of dasatinib-induced apoptosis in CLL cells corresponds to the concomitant decrease in the phosphorylation of the direct SFK substrates Syk and phospholipase C- $\gamma$ (Song et al., 2010). Signaling analysis during SFK inhibition thus contributed to the rationale for pre-clinical assessment of Syk inhibitors on CLL cells (Baudot et al., 2009; Buchner et al., 2009). For another second generation dual $\mathrm{Abl} / \mathrm{Src}$ inhibitor, bosutinib, inhibition of the receptor tyrosine kinase Axl was found to be partially responsible for its apoptosis induction in CLL cells (Ghosh et al., 2010).

Inhibition of $\mathrm{Abl}$ does not reduce viability of CLL cells on its own, but can sensitize CLL cells for chemotherapeutic agents, e.g. chlorambucil, by interfering with DNA repair (Aloyz et al., 2004). Inhibitors of the delta isoform of the catalytic p110 subunit of phosphatidylinositol-3-kinase (PI3K) show moderate efficiencies on primary CLL lymphocytes without activation that contrast the promising effects in clinical trials. The observed pre-clinical efficiency of the PI3K-delta inhibitor CAL-101 is not abrogated by micro-environmental stimulation and other cell types, while other cell types, e.g. natural killer cells are not influenced by CAL-101 (Herman et al., 2010).

\section{Pre-clinical assessment of monoclonal antibodies}

Apart from small molecules, monoclonal antibodies constitute another group of targeted therapeutics for the treatment of CLL. This group includes the first biological anti-tumor 
agent, namely the CD20 antibody rituximab. As a common cell surface antigen of all B cells except stem or plasma cells, CD20 has become a very effective antibody target for the treatment of B cell malignancies (Molina, 2008) including CLL despite variable surface expression on CLL cells. Together with the monoclonal anti-CD52 antibody alemtuzumab, rituximab thus may be counted among the most efficient targeted treatment options for CLL achieved so far. In a recent phase III trial inclusion of rituximab was shown to substantially improve the established fludarabine / cyclophosphamide chemotherapy regimen (Hallek et al., 2010).

Apart from DCD induction in tumor cells, monoclonal antibodies exert their action via Fcmediated functions, namely CDC, ADCC and phagocytosis (Jaglowski et al., 2010; Olszewski \& Grossbard, 2004) (Fig. 3). Therefore an assessment of antibody effects on CLL cells ex vivo can either be performed on freshly isolated CLL cells in separate dedicated assays for each mentioned mechanisms, or in a comprehensive assay from whole (Table 2). For assessing antibody effects on isolated CLL cells, the same procedures as for other antiCLL agents can only be applied for the determination of DCD. For instance DCD induction by rituximab in freshly isolated CLL cells was assessed according to viable cell counts, metabolic activity and phosphatidylserine exposure and was found variable among individual samples and considerably smaller than in lymphoma cell lines (Patz et al., 2011; Stanglmaier et al., 2004). Since DCD induction in primary CLL cells may constitute only a minor fraction of overall B cell depletion as in the case of rituximab (Voso et al., 2002), it is indispensable to additionally assess Fc-mediated mechanisms. For performing ADCC assays on isolated CLL lymphocytes, effector cells need to be externally added, e.g. autologous or heterologous peripheral blood mononuclear cells or a natural killer cell line (Weitzman et al., 2009). Similarly, CDC can be assessed by monitoring changes in the membrane integrity of CLL cells after incubation in medium containing high concentrations of complete as compared to heat-inactivated serum (Golay et al., 2000; Patz et al., 2011).

\section{Mechanism}

\section{Isolated CLL cells}

DCD Cytotoxicity or viability assays

$\mathrm{CDC}$

ADCC
Comparison of effects with complete or heat-inactivated serum

Externally added effector cells

\section{Whole blood}

Requires distinction of CLL lymphocytes from other cell populations

Complement inhibition by cobra venom factor

Blocking antibodies for Fc receptors

Table 2. Determination and dissection of different mechanisms of antibody-induced cytotoxicity.

As an alternative to these separate assays, we applied a B cell depletion assay from whole blood encompassing Fc-mediated antibody-induced cytotoxicity. This assay is based on the enumeration of B lymphocytes in differentially treated whole blood samples after staining the general, B- and T- lymphocyte antigens CD45, CD19 and CD3 using three color flow cytometry and commercially available fluorescently labeled immunoreagents. B cell depletion can be calculated from the B cell counts in antibody-treated versus untreated control samples. B/T cell ratios with the $\mathrm{T}$ cell population as an internal standard can be 
used for this calculation, if $\mathrm{T}$ cell counts are proven to be unaffected by the antibody treatment. Alternatively absolute B cell counts can be determined using externally added fluorescent counting beads. In part the contributions of DCD, CDC and ADCC to the observed B cell depletion from whole blood samples can be dissected. Thus, we were able to show a substantial contribution of ADCC to the B cell depletion by the novel type II CD20 antibody GA101 (Moessner et al., 2010) by blocking the interaction of FcyIIIa on NK cells and macrophages and the Fc exposed on antibody-coated target cells by incubation with anti-CD16 antibody in whole blood from healthy donors but not CLL patients (Patz et al., 2011). In summary, flow cytometric determination of B cell depletion from whole blood has the potential of comparing antibody effects on individual CLL samples and of predicting clinical responses.

Resistance mechanisms to anti-CLL antibodies have been unraveled by pre-clinical models and some of the influences interfering with antibody efficacy may be recapitulated in the the present B cell depletion from whole blood samples (Table 3) (Reslan et al., 2009). Thus the shape of the dose response curves of GA101 or mAb37.1 observed in the B cell depletion assay (Krause et al., 2011; Patz et al., 2011) is of saturation type and suggests an influence on antibody effects of individually different levels of endogenous human IgG in the assay matrix (Preithner et al., 2006). Similarly, varying ratios of effector to target cells, the Phe158Val polymorphism of FcyIIIa (Cartron et al., 2002) as well as complement depletion (Kennedy et al., 2004) will influence B cell depletion from whole blood samples. Thus, the assay described here has the advantage of reflecting both, the efficiency of antibody-induced $B$ cell depletion and the potential to supply host-dependent immune functions and thus should be able to predict at the individual level the clinical efficiency of therapeutics assayed in vitro.

\section{Influence}

Antigen density on target cells

Complement depletion

Complement inhihibitors CD59 and CD55

Ratio of effector to target cells

Plasma levels of IgG

Fc receptor polymorphisms

\section{References}

Golay et al., 2001, Patz et al., 2011

Kennedy et al., 2004

Golay et al., 2001

Preithner et al., 2006

Cartron et al., 2002

Table 3. Influences on antibody efficacy in a whole blood matrix.

\section{Conclusions}

Due to the dependence of CLL lymphocytes on their micro-environment, the predictive value of simple cytotoxicity assays on freshly isolated CLL cells can be enhanced by activating CLL cells using procedures that mimic certain micro-environmental stimuli. In the case of monoclonal antibodies, effector cells and complement system need to be included in order to comprise indirect antibody-mediated mechanisms. For arriving at valid predictions, results of the individualized in vitro sensitivity testing should be linked to mechanistic and biochemical target validation studies, ideally involving genetically defined systems. Remarkably three major topics addressed in this chapter, namely the importance of accompanying signaling analysis, consideration of the micro-environment of CLL cells and 
combination with chemotherapeutic agents conceptually strongly overlap with general targeting strategies in contemporary pre-clinical anticancer drug discovery (Caponigro \& Sellers, 2011).

\section{Acknowledgements}

Work in our laboratory has been supported by grants from the German Cancer Aid, German José Carreras Leukemia Foundation and CLL Global Research Foundation.

\section{References}

Aleskog, A., Norberg, M., Nygren, P., Rickardson, L., Kanduri, M., Tobin, G., Aberg, M., Gustafsson, M.G., Rosenquist, R. \& Lindhagen, E. (2008). Rapamycin shows anticancer activity in primary chronic lymphocytic leukemia cells in vitro, as single agent and in drug combination Leuk Lymphoma , 49, 2333-43.

Aloyz, R., Grzywacz, K., Xu, Z.Y., Loignon, M., Alaoui-Jamali, M.A. \& Panasci, L. (2004). Imatinib sensitizes CLL lymphocytes to chlorambucil Leukemia , 18, 409-14.

Baudot, A.D., Jeandel, P.Y., Mouska, X., Maurer, U., Tartare-Deckert, S., Raynaud, S.D., Cassuto, J.P., Ticchioni, M. \& Deckert, M. (2009). The tyrosine kinase Syk regulates the survival of chronic lymphocytic leukemia B cells through PKCdelta and proteasome-dependent regulation of Mcl-1 expression Oncogene , 28, 3261-73.

Bosanquet, A.G., Richards, S.M., Wade, R., Else, M., Matutes, E., Dyer, M.J., Rassam, S.M., Durant, J., Scadding, S.M., Raper, S.L., Dearden, C.E. \& Catovsky, D. (2009). Drug cross-resistance and therapy-induced resistance in chronic lymphocytic leukaemia by an enhanced method of individualised tumour response testing $\mathrm{Br} J$ Haematol , 146, 384-95.

Buchner, M., Fuchs, S., Prinz, G., Pfeifer, D., Bartholome, K., Burger, M., Chevalier, N., Vallat, L., Timmer, J., Gribben, J.G., Jumaa, H., Veelken, H., Dierks, C. \& Zirlik, K. (2009). Spleen tyrosine kinase is overexpressed and represents a potential therapeutic target in chronic lymphocytic leukemia Cancer Res , 69, 5424-32.

Burger, J.A., Ghia, P., Rosenwald, A. \& Caligaris-Cappio, F. (2009). The microenvironment in mature B-cell malignancies: a target for new treatment strategies Blood, 114, 3367-75.

Burger, J.A. \& Kipps, T.J. (2006). CXCR4: a key receptor in the crosstalk between tumor cells and their microenvironment Blood , 107, 1761-7.

Caponigro, G. \& Sellers, W.R. (2011). Advances in the preclinical testing of cancer therapeutic hypotheses Nat Rev Drug Discov , 10, 179-87.

Cartron, G., Dacheux, L., Salles, G., Solal-Celigny, P., Bardos, P., Colombat, P. \& Watier, H. (2002). Therapeutic activity of humanized anti-CD20 monoclonal antibody and polymorphism in IgG Fc receptor FcgammaRIIIa gene Blood, 99, 754-8.

Collins, I. \& Workman, P. (2006). New approaches to molecular cancer therapeutics Nat Chem Biol , 2, 689-700.

Contri, A., Brunati, A.M., Trentin, L., Cabrelle, A., Miorin, M., Cesaro, L., Pinna, L.A., Zambello, R., Semenzato, G. \& Donella-Deana, A. (2005). Chronic lymphocytic leukemia B cells contain anomalous Lyn tyrosine kinase, a putative contribution to defective apoptosis J Clin Invest , 115, 369-78. 
Crespo, M., Bosch, F., Villamor, N., Bellosillo, B., Colomer, D., Rozman, M., Marce, S., Lopez-Guillermo, A., Campo, E. \& Montserrat, E. (2003). ZAP-70 expression as a surrogate for immunoglobulin-variable-region mutations in chronic lymphocytic leukemia $N$ Engl J Med , 348, 1764-75.

Decker, T., Hipp, S., Ringshausen, I., Bogner, C., Oelsner, M., Schneller, F. \& Peschel, C. (2003). Rapamycin-induced G1 arrest in cycling B-CLL cells is associated with reduced expression of cyclin D3, cyclin E, cyclin A, and survivin Blood , 101, 278-85.

Decker, T., Schneller, F., Sparwasser, T., Tretter, T., Lipford, G.B., Wagner, H. \& Peschel, C. (2000). Immunostimulatory CpG-oligonucleotides cause proliferation, cytokine production, and an immunogenic phenotype in chronic lymphocytic leukemia B cells Blood, 95, 999-1006.

Deglesne, P.A., Chevallier, N., Letestu, R., Baran-Marszak, F., Beitar, T., Salanoubat, C., Sanhes, L., Nataf, J., Roger, C., Varin-Blank, N. \& Ajchenbaum-Cymbalista, F. (2006). Survival response to B-cell receptor ligation is restricted to progressive chronic lymphocytic leukemia cells irrespective of Zap70 expression Cancer Res , 66, 7158-66.

Druker, B.J., Talpaz, M., Resta, D.J., Peng, B., Buchdunger, E., Ford, J.M., Lydon, N.B., Kantarjian, H., Capdeville, R., Ohno-Jones, S. \& Sawyers, C.L. (2001). Efficacy and safety of a specific inhibitor of the BCR-ABL tyrosine kinase in chronic myeloid leukemia N Engl J Med , 344, 1031-7.

Eichhorst, B., Goede, V. \& Hallek, M. (2009). Treatment of elderly patients with chronic lymphocytic leukemia Leuk Lymphoma , 50, 171-8.

Gandhi, V. (2010). Targeting kinases in CML CLL Blood , 116, 1999-2000.

Gehrke, I., Gandhirajan, R.K., Poll-Wolbeck, S.J., Hallek, M. \& Kreuzer, K.A. (2011). Bone marrow stromal cell-derived VEGF rather than CLL cell-derived VEGF is essential for the apoptotic resistance of cultured CLL cells $\mathrm{Mol} \mathrm{Med} \mathrm{.}$

Ghosh, A.K., Secreto, C., Boysen, J., Sassoon, T., Shanafelt, T.D., Mukhopadhyay, D. \& Kay, N.E. (2010). The novel receptor tyrosine kinase Axl is constitutively active in B-cell chronic lymphocytic leukemia and acts as a docking site of nonreceptor kinases: implications for therapy Blood, 117, 1928-37.

Golay, J., Bologna, L., Andre, P.A., Buchegger, F., Mach, J.P., Boumsell, L. \& Introna, M. (2010). Possible misinterpretation of the mode of action of therapeutic antibodies in vitro: homotypic adhesion and flow cytometry result in artefactual direct cell death Blood , 116, 3372-3; author reply 3373-4.

Golay, J., Zaffaroni, L., Vaccari, T., Lazzari, M., Borleri, G.M., Bernasconi, S., Tedesco, F., Rambaldi, A. \& Introna, M. (2000). Biologic response of B lymphoma cells to antiCD20 monoclonal antibody rituximab in vitro: CD55 and CD59 regulate complement-mediated cell lysis Blood, 95, 3900-8.

Groves, M.J., Maccallum, S., Boylan, M.T., Coates, P.J. \& Tauro, S. (2009). The annexin-V assay reflects susceptibility to in vitro membrane damage in chronic lymphocytic leukemia and may overestimate cell death Am J Hematol, 84, 196-7.

Hallaert, D.Y., Jaspers, A., van Noesel, C.J., van Oers, M.H., Kater, A.P. \& Eldering, E. (2008). c-Abl kinase inhibitors overcome CD40-mediated drug resistance in CLL: implications for therapeutic targeting of chemoresistant niches Blood, 112, 5141-9.

Hallek, M., Cheson, B.D., Catovsky, D., Caligaris-Cappio, F., Dighiero, G., Dohner, H., Hillmen, P., Keating, M.J., Montserrat, E., Rai, K.R. \& Kipps, T.J. (2008). Guidelines 
for the diagnosis and treatment of chronic lymphocytic leukemia: a report from the International Workshop on Chronic Lymphocytic Leukemia updating the National Cancer Institute-Working Group 1996 guidelines Blood , 111, 5446-56.

Hallek, M., Fischer, K., Fingerle-Rowson, G., Fink, A.M., Busch, R., Mayer, J., Hensel, M., Hopfinger, G., Hess, G., von Grunhagen, U., Bergmann, M., Catalano, J., Zinzani, P.L., Caligaris-Cappio, F., Seymour, J.F., Berrebi, A., Jager, U., Cazin, B., Trneny, M., Westermann, A., Wendtner, C.M., Eichhorst, B.F., Staib, P., Buhler, A., Winkler, D., Zenz, T., Bottcher, S., Ritgen, M., Mendila, M., Kneba, M., Dohner, H. \& Stilgenbauer, S. (2010). Addition of rituximab to fludarabine and cyclophosphamide in patients with chronic lymphocytic leukaemia: a randomised, open-label, phase 3 trial Lancet , 376, 1164-74.

Hamblin, T.J. (2009). Just exactly how common is CLL? Leuk Res , 33, 1452-3.

Hamblin, T.J., Davis, Z., Gardiner, A., Oscier, D.G. \& Stevenson, F.K. (1999). Unmutated Ig $\mathrm{V}(\mathrm{H})$ genes are associated with a more aggressive form of chronic lymphocytic leukemia Blood , 94, 1848-54.

Hamblin, T.J., Orchard, J.A., Ibbotson, R.E., Davis, Z., Thomas, P.W., Stevenson, F.K. \& Oscier, D.G. (2002). CD38 expression and immunoglobulin variable region mutations are independent prognostic variables in chronic lymphocytic leukemia, but CD38 expression may vary during the course of the disease Blood, 99, 1023-9.

Herman, S.E., Gordon, A.L., Wagner, A.J., Heerema, N.A., Zhao, W., Flynn, J.M., Jones, J., Andritsos, L., Puri, K.D., Lannutti, B.J., Giese, N.A., Zhang, X., Wei, L., Byrd, J.C. \& Johnson, A.J. (2010). Phosphatidylinositol 3-kinase-delta inhibitor CAL-101 shows promising preclinical activity in chronic lymphocytic leukemia by antagonizing intrinsic and extrinsic cellular survival signals Blood ,116, 2078-88.

Jaglowski, S.M., Alinari, L., Lapalombella, R., Muthusamy, N. \& Byrd, J.C. (2010). The clinical application of monoclonal antibodies in chronic lymphocytic leukemia Blood , 116, 3705-14.

Jahrsdorfer, B., Hartmann, G., Racila, E., Jackson, W., Muhlenhoff, L., Meinhardt, G., Endres, S., Link, B.K., Krieg, A.M. \& Weiner, G.J. (2001). CpG DNA increases primary malignant B cell expression of costimulatory molecules and target antigens J Leukoc Biol , 69, 81-8.

Kennedy, A.D., Beum, P.V., Solga, M.D., DiLillo, D.J., Lindorfer, M.A., Hess, C.E., Densmore, J.J., Williams, M.E. \& Taylor, R.P. (2004). Rituximab infusion promotes rapid complement depletion and acute CD20 loss in chronic lymphocytic leukemia J Immunol , 172, 3280-8.

Kepp, O., Galluzzi, L., Lipinski, M., Yuan, J. \& Kroemer, G. (2011). Cell death assays for drug discovery Nat Rev Drug Discov , 10, 221-37.

Koopman, G., Reutelingsperger, C.P., Kuijten, G.A., Keehnen, R.M., Pals, S.T. \& van Oers, M.H. (1994). Annexin V for flow cytometric detection of phosphatidylserine expression on B cells undergoing apoptosis Blood , 84, 1415-20.

Krause, G. \& Hallek, M. (2011). On the assessment of dasatinib-induced autophagy in CLL Leuk Res , 35, 137-8.

Krause, G., Patz, M., Isaeva, P., Wigger, M., Baki, I., Vondey, V., Kerwien, S., Kuckertz, M., Brinker, R., Claasen, J., Frenzel, L.P., Wendtner, C.M., Heider, K.H. \& Hallek, M. (2011). Action of novel CD37 antibodies on chronic lymphocytic leukemia cells Leukemia , in press. 
Krieg, A.M. (2006). Therapeutic potential of Toll-like receptor 9 activation Nat Rev Drug Discov , 5, 471-84.

Lindhagen E, Nygren P, Larsson R (2008) The fluorometric microculture cyto-toxicity assay. Nat Protoc , 3 (8): 1364-9.

Lilienthal, N., Prinz, C., Peer-Zada, A.A., Doering, M., Ba, L.A., Hallek, M., Jacob, C. \& Herling, M. (2011). Targeting the disturbed redox equilibrium in chronic lymphocytic leukemia by novel reactive oxygen species-catalytic 'sensor/effector' compounds Leuk Lymphoma , 52, 1407-11.

Majolini, M.B., Boncristiano, M. \& Baldari, C.T. (1999). Dysregulation of the protein tyrosine kinase LCK in lymphoproliferative disorders and in other neoplasias. Leuk Lymphoma , 35, 245-54.

Mayr, C., Speicher, M.R., Kofler, D.M., Buhmann, R., Strehl, J., Busch, R., Hallek, M. \& Wendtner, C.M. (2006). Chromosomal translocations are associated with poor prognosis in chronic lymphocytic leukemia Blood , 107, 742-51.

Messmer, D., Fecteau, J.F., O'Hayre, M., Bharati, I.S., Handel, T.M. \& Kipps, T.J. (2011). Chronic lymphocytic leukemia cells receive RAF-dependent survival signals in response to CXCL12 that are sensitive to inhibition by sorafenib Blood, 117, 882-9.

Moessner, E., Brunker, P., Moser, S., Puntener, U., Schmidt, C., Herter, S., Grau, R., Gerdes, C., Nopora, A., van Puijenbroek, E., Ferrara, C., Sondermann, P., Jäger, C., Strein, P., Fertig, G., Friess, T., Schuell, C., Bauer, S., Dal Porto, J., Del Nagro, C., Dabbagh, K., Dyer, M.J.S., Poppema, S., Klein, C. \& Umana, P. (2010). Increasing the efficacy of CD20 antibody therapy through the engineering of a new type II anti-CD20 antibody with enhanced direct and immune effector cell-mediated B-cell cytotoxicity Blood , 115, 4393-4402.

Molina, A. (2008). A decade of rituximab: improving survival outcomes in non-Hodgkin's lymphoma Annu Rev Med , 59, 237-50.

Munk Pedersen, I. \& Reed, J. (2004). Microenvironmental interactions and survival of CLL B-cells Leuk Lymphoma , 45, 2365-72.

Olszewski, A.J. \& Grossbard, M.L. (2004). Empowering targeted therapy: lessons from rituximab Sci STKE, 2004, pe30.

Patz, M., Isaeva, P., Forcob, N., Muller, B., Frenzel, L.P., Wendtner, C.M., Klein, C., Umana, P., Hallek, M. \& Krause, G. (2011). Comparison of the in vitro effects of the antiCD20 antibodies rituximab and GA101 on chronic lymphocytic leukaemia cells $\mathrm{Br} \mathrm{J}$ Haematol , 152, 295-306.

Pharmingen. (1998). Apoptosis. Applied reagents and technologies. 2nd edition.

Pleyer, L., Egle, A., Hartmann, T.N. \& Greil, R. (2009). Molecular and cellular mechanisms of CLL: novel therapeutic approaches Nat Rev Clin Oncol , 6, 405-18.

Preithner, S., Elm, S., Lippold, S., Locher, M., Wolf, A., da Silva, A.J., Baeuerle, P.A. \& Prang, N.S. (2006). High concentrations of therapeutic IgG1 antibodies are needed to compensate for inhibition of antibody-dependent cellular cytotoxicity by excess endogenous immunoglobulin G Mol Immunol , 43, 1183-93.

Puttini, M., Coluccia, A.M., Boschelli, F., Cleris, L., Marchesi, E., Donella-Deana, A., Ahmed, S., Redaelli, S., Piazza, R., Magistroni, V., Andreoni, F., Scapozza, L., Formelli, F. \& Gambacorti-Passerini, C. (2006). In vitro and in vivo activity of SKI-606, a novel SrcAbl inhibitor, against imatinib-resistant Bcr-Abl+ neoplastic cells Cancer Res , 66, 11314-22. 
Reslan, L., Dalle, S. \& Dumontet, C. (2009). Understanding and circumventing resistance to anticancer monoclonal antibodies MAbs , 1, 222-9.

Seiffert, M., Schulz, A., Ohl, S., Dohner, H., Stilgenbauer, S. \& Lichter, P. (2010). Soluble CD14 is a novel monocyte-derived survival factor for chronic lymphocytic leukemia cells, which is induced by CLL cells in vitro and present at abnormally high levels in vivo Blood , 116, 4223-30.

Shah, N.P., Tran, C., Lee, F.Y., Chen, P., Norris, D. \& Sawyers, C.L. (2004). Overriding imatinib resistance with a novel ABL kinase inhibitor Science, 305, 399-401.

Song, Z., Lu, P., Furman, R.R., Leonard, J.P., Martin, P., Tyrell, L., Lee, F.Y., Knowles, D.M., Coleman, M. \& Wang, Y.L. (2010). Activities of SYK and PLCgamma2 predict apoptotic response of CLL cells to SRC tyrosine kinase inhibitor dasatinib Clin Cancer Res , 16, 587-99.

Stanglmaier, M., Reis, S. \& Hallek, M. (2004). Rituximab and alemtuzumab induce a nonclassic, caspase-independent apoptotic pathway in B-lymphoid cell lines and in chronic lymphocytic leukemia cells Ann Hematol , 83, 634-45.

Stevenson, F.K. \& Caligaris-Cappio, F. (2004). Chronic lymphocytic leukemia: revelations from the B-cell receptor Blood , 103, 4389-95.

Veldurthy, A., Patz, M., Hagist, S., Pallasch, C.P., Wendtner, C.M., Hallek, M. \& Krause, G. (2008). The kinase inhibitor dasatinib induces apoptosis in chronic lymphocytic leukemia cells in vitro with preference for a subgroup of patients with unmutated IgVH genes Blood , 112, 1443-52.

Vogler, M., Butterworth, M., Majid, A., Walewska, R.J., Sun, X.M., Dyer, M.J. \& Cohen, G.M. (2009). Concurrent up-regulation of BCL-XL and BCL2A1 induces approximately 1000-fold resistance to ABT-737 in chronic lymphocytic leukemia Blood , 113, 440313.

Voso, M.T., Pantel, G., Rutella, S., Weis, M., D'Alo, F., Urbano, R., Leone, G., Haas, R. \& Hohaus, S. (2002). Rituximab reduces the number of peripheral blood B-cells in vitro mainly by effector cell-mediated mechanisms Haematologica , 87, 918-25.

Weisberg, E., Manley, P.W., Cowan-Jacob, S.W., Hochhaus, A. \& Griffin, J.D. (2007). Second generation inhibitors of BCR-ABL for the treatment of imatinib-resistant chronic myeloid leukaemia Nat Rev Cancer , 7, 345-56.

Weitzman, J., Betancur, M., Boissel, L., Rabinowitz, A.P., Klein, A. \& Klingemann, H. (2009). Variable Contribution of Monoclonal Antibodies to ADCC in patients with chronic lymphocytic leukemia Leuk Lymphoma, 1-8.

Wickremasinghe, R.G., Prentice, A.G. \& Steele, A.J. (2011). Aberrantly activated antiapoptotic signalling mechanisms in chronic lymphocytic leukaemia cells: clues to the identification of novel therapeutic targets Br J Haematol, 153, 545-56.

Zenz, T., Mertens, D., Kuppers, R., Dohner, H. \& Stilgenbauer, S. (2010). From pathogenesis to treatment of chronic lymphocytic leukaemia Nat Rev Cancer , 10, 37-50.

Zhang G, Gurtu V, Kain SR\& Yan G. (1997) Early detection of apoptosis using a fluorescent conjugate of annexin V. Biotechniques , 23, 525-31. 


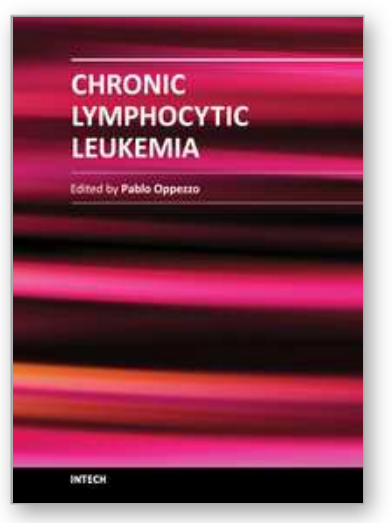

\author{
Chronic Lymphocytic Leukemia \\ Edited by Dr. Pablo Oppezzo
}

ISBN 978-953-307-881-6

Hard cover, 448 pages

Publisher InTech

Published online 10, February, 2012

Published in print edition February, 2012

B-cell chronic lymphocytic leukemia (CLL) is considered a single disease with extremely variable course, and survival rates ranging from months to decades. It is clear that clinical heterogeneity reflects biologic diversity with at least two major subtypes in terms of cellular proliferation, clinical aggressiveness and prognosis. As CLL progresses, abnormal hematopoiesis results in pancitopenia and decreased immunoglobulin production, followed by nonspecific symptoms such as fatigue or malaise. A cure is usually not possible, and delayed treatment (until symptoms develop) is aimed at lengthening life and decreasing symptoms. Researchers are playing a lead role in investigating CLL's cause and the role of genetics in the pathogenesis of this disorder. Research programs are dedicated towards understanding the basic mechanisms underlying CLL with the hope of improving treatment options.

\title{
How to reference
}

In order to correctly reference this scholarly work, feel free to copy and paste the following:

Günter Krause, Mirjam Kuckertz, Susan Kerwien, Michaela Patz and Michael Hallek (2012). In Vitro Sensitivity Testing in the Assessment of Anti-CLL Drug Candidates, Chronic Lymphocytic Leukemia, Dr. Pablo Oppezzo (Ed.), ISBN: 978-953-307-881-6, InTech, Available from: http://www.intechopen.com/books/chroniclymphocytic-leukemia/in-vitro-sensitivity-testing-in-the-assessment-of-anti-cll-drug-candidates

\section{INTECH}

open science | open minds

\author{
InTech Europe \\ University Campus STeP Ri \\ Slavka Krautzeka 83/A \\ 51000 Rijeka, Croatia \\ Phone: +385 (51) 770447 \\ Fax: +385 (51) 686166 \\ www.intechopen.com
}

\author{
InTech China \\ Unit 405, Office Block, Hotel Equatorial Shanghai \\ No.65, Yan An Road (West), Shanghai, 200040, China \\ 中国上海市延安西路65号上海国际贵都大饭店办公楼405单元 \\ Phone: +86-21-62489820 \\ Fax: $+86-21-62489821$
}


(C) 2012 The Author(s). Licensee IntechOpen. This is an open access article distributed under the terms of the Creative Commons Attribution 3.0 License, which permits unrestricted use, distribution, and reproduction in any medium, provided the original work is properly cited. 